\title{
Termal Enerji Depolama Sistemlerinin Uygulanabilirliğinin İncelenmesi
}

\author{
${ }^{* 1}$ Beytullah Eren ve ${ }^{2}$ Muammer Köksal \\ *1Çevre Mühendisliği Bölümü, Mühendislik Fakültesi, Sakarya Üniversitesi, 54187, Sakarya, Türkiye \\ ${ }^{2}$ Lisans, Çevre Mühendisliği Bölümü, Mühendislik Fakültesi, Sakarya Üniversitesi, 54187, Sakarya, Türkiye
}

\begin{abstract}
Özet
Günümüzde tüketilen enerjinin büyük bir kısmı fosil yakıt kullanılarak enerji üreten sistemlerden elde edilmektedir. Fosil yakıtların kullanımın artması sonucu atmosfere salınan $\mathrm{CO}_{2} \mathrm{emisyonu}$ artmakta bu da küresel ısınmaya dolayısı ile iklim değiş̧ikliklerine yol açmaktadır. Kaynaklarımızın sınırlı olduğu düşünüldüğünde enerji ihtiyacının karşılanması var olan kaynakların daha verimli olarak kullanılması gerektiği sonucunu doğurmaktadır. Enerji ihtiyacını yenilenebilir enerji kaynaklarından mevcut teknolojiyle ve elde edilebilir imkânlarla karşılamak ve var olan yaşam döngüsü kısa olan yenilenebilir enerji kaynaklarının da çevresel etkilerini en aza indirmek gerekir. Enerji gereksiniminin \%60'dan fazlası ithal kaynaklardan sağlanan ülkemizde kendi doğal kaynaklarından yararlanmasına olanak veren termal enerji depolama sistemleriyle ülke ekonomisine önemli katkılar sağlanabilir. Ayrıca TED sistemleri ile ekonomikliğin yanı sıra enerji güvenirliliği ve sürekliliği noktasında da önemli katkılar sağlayacaktır.
\end{abstract}

Anahtar Kelimeler:Termal enerji depolama (TED), yenilenebilir enerji, tasarım, maliyet analizi

\begin{abstract}
Today, most of the energy consumed is obtained from the systems that produce energy by using fossil fuel.As a result of increasing use of fossil fuels, $\mathrm{CO} 2$ emissions to the atmosphere increase and this leads to global warming and climate change.Considering that our resources are limited, meeting the energy demand shows that the existing resources should be used more efficiently.It is necessary to meet the energy need from renewable energy sources with available technology and available facilities and to minimize the environmental impact of renewable energy sources with short life cycles.In our country where more than $60 \%$ of the energy requirement is provided from imported sources, significant contributions can be made to the national economy with thermal energy storage systems that enable it to benefit from its own natural resources.In addition, it will make significant contributions to energy reliability and sustainability with TES systems.
\end{abstract}

Key words:Thermal Energy Storage (TES), renewable energy, design, cost analysis

*SorumluYazar: Adres: Çevre Mühendisliği Bölümü, Mühendislik Fakültesi, Sakarya Üniversitesi, 54187, Sakarya, Türkiye. E-mail: beren@ sakarya.edu.tr, Tel: +902642955642 


\section{Giriş}

Günümüzde enerji, gerek elde etme yöntemi gerekse gittikçe artan maliyetlerle ulaşılması zor bir hal almıştır. $\mathrm{Bu}$ nedenle enerji elde etmede yenilenebilir enerji kaynaklarından faydalanmanın artırılması ve daha verimli kullanılabilmesi olgusu üzerinde yapılan çalışmaların sayısı gün geçtikçe artmaktadır. Dünya nüfusunun ve endüstrileşmeni hızla artması enerji ihtiyacının da hızla artması anlamına gelmektedir. Günümüzde tüketilen enerjinin büyük bir kısmı fosil yakıt kullanılarak enerji üreten sistemlerden elde edilmektedir.Fosil yakıtların kullanımın artması sonucu atmosfere salınan $\mathrm{CO}_{2}$ emisyonu artmakta bu da küresel 1sınmaya dolayısı ile iklim değişikliklerine yol açmaktadır. Kaynaklarımızın sınırlı olduğu düşünüldüğünde enerji ihtiyacının karşılanması var olan kaynakların daha verimli olarak kullanılması gerektiği sonucunu doğurmaktadır.Enerji ihtiyacını yenilenebilir enerji kaynaklarından mevcut teknolojiyle ve elde edilebilir imkânlarla karşılamak ve var olan yaşam döngüsü kısa olan yenilenebilir enerji kaynaklarının da çevresel etkilerini en aza indirmek gerekir. Bu nedenle verimi düşük ve yaşam döngüsü kısa olan sistemler yerine belki maliyetleri bir miktar daha yüksek olmasına karşı yaşam döngüsü daha uzun olan sistemlere geçişi hızlandırmak daha olumlu olacaktır. Her üretimin dünyada bırakmış olduğu ayak izini hızlı bir şekilde düşürmek gelecek kuşaklar için bir gerekliliktir.

Enerji depolama sistemlerinin amacı enerji talebinin olduğu durumlarda kullanılmak üzere enerji üretimin talepten fazla olduğu zamanlarda enerjinin depolanmasıdır. Termal Enerji Depolama (TED), bir depolama ortamını 1sıtmak veya soğutmak suretiyle 1sı enerjisini depolayan ve böylece depolanan enerjinin daha sonra ısitma ve soğutma uygulamaları amaciyla kullanılabileceği bir teknolojidir[1].Termal depolama bir "1sı aküsü” olarak düşünülebilir; çünkü bu sistemde 1S1 enerjisi daha sonra kullanılmak üzere şekilde depolanmaktadır.Bir enerji sisteminde TED kullanmanın avantajları, enerji verimliliğinde ve güvenilirliğinde artış, yenilenebilir enerji kaynaklarından faydalanarak enerjide ekonomiklik, yatırım ve işletme maliyetlerinde azalma ve daha az karbondioksit $\left(\mathrm{CO}_{2}\right)$ emisyonu salınımı dolayısı ile çevre kirliliğinde azalma olarak sayılabilir[2, 3].

Isı depolama sistemlerinde her sistemin kendine has özellikleri olması sebebiyle bir standardı yoktur. Isı depolama sistemleri, iklime, güneşlenme süresine, ihtiyaçlara, isıtılacak ortamın yapısına, enerji ihtiyacının karşılanabilmesi için maliyetine katlanılabilirliğe bağlı olarak değişiklik göstermektedir.Termal 1sı depolama sistemleri temelde 4 ana aşamadan oluşur. Bunlar ısının depolanabileceği bir materyal, 1sıyı iletecek bir ortam, 1sıyı iletme esnasında kullanılacak güç ve 1sı kaynağı şeklindedir[4].

Ülkemizde termal enerji depolama konusunda şimdiye kadar yeterli düzeyde çalışma yapılmamıştır. Oysa ülkemiz birçok Avrupa ülkesinegöre yenilenebilir enerjiler açısından, özellikle de güneş açısından çok verimli bölgede yer almaktadır. Fakat gün geçtikçe her ne kadar 
bu alanda olumlu gelişmeler yaşanmaktaysa da hem teknoloji hem de kullanılabilirlik açısından henüz mevcut potansiyeli en etkili şekilde kullanılacak seviyelere gelinmemiştir. Güneş enerjisinin termal olarak depolanması ve gerektiğinde kullanılması güneşlenme süresinin ülkemize göre çok az olduğu Almanya'da çok uzun yıllardan beri kullanılmaktadır. Bu çalışmadaekonomik ömrü 20-30 yıl olan termal enerji depolama sitemlerinin farkındalığının sağlanması ve aynı zamanda eldeki imkânlarla yapılabilirliğinin gösterilmesi hedeflenmektedir. Asıl amaç ise her bina için ısınma ve enerji ihtiyacının karşılanmasında ithal enerji kaynaklarının yerine, uygulanabilir bir tasarımla ülkemiz için enerji maliyetlerinin daha aza indirgenmesine katkı sağlamak ve bu yöndeki teknolojilerin artmasına imkân sağlamaktır.

\section{Yöntem}

\subsection{Termal Enerji Depolama}

Tüm termal depolama sistemleri şarj, depolama ve deşarj olmak üzere üç fonksiyona sahiptir. Şarj,depolama ortamına 1Sı sağlamak için bir 1sı kaynağı kullanılması, Depolama, daha sonra kullanmak üzere ısının depolanması ve deşarjise depolanan ısının depolama ortamını enerji ihtiyacınıkarşılamak üzerekontrollü bir şekilde terk etmesi olarak ifade edilebilir[4].

Tüm termal depolama sistemleri üç temel bölümden oluşmaktadır;

1) Isı depolama malzemesi ve eğer mevcutsa depolama malzemesinin içinde bulunacağı bir kap (konteynir,depo),

2) Depolama malzemesine 1sı transferini kolaylaştırmak için bir ısı değiştirici,

3) Termal depolamanın şarj edilmesini ve boşaltılmasını kolaylaştıran bir kontrol sistemi[4].

Fonksiyon ve temel parçalardaki benzerliklere rağmen, termal depolama sistemlerinin birçok değişik konfigürasyonu da vardır. Birçoğu, belirli bir yapı ve uygulama için özel olarak tasarlanmıştır ve benzersizdir. Diğerleri ise sadece uygulamaya göre küçük değişiklikler gösteren genel anlamda benzer tasarıma sahip sistemlerdir[4].

\subsection{Termal Enerji Depolama Yöntemleri}

Termal enerji depolama yöntemlerinde termokimyasal 1S1 depolama, gizli 1sı depolama ve duyulur ısı depolama olmak üzere üç tür yöntem kullanılmaktadır.Duyulur 1sı depolama, 1sının iç enerji olarak depolanması esasına dayanmaktadır.Gizli 1sı depolama, bir materyali faz değişimi gerçekleşene kadar ısıtma yöntemi ilesağlanmaktadır. Katı halden sıvı hale ya da sıvı halden gaz haline geçen materyal, busayede 1sıyı depolamış olur. Termokimyasal 1sı depolama ise tersinir endotermik kimyasal reaksiyonlardan termal enerji depolamakiçin yararlanılması esasına dayanır. Kimyasal 1sı, kimyasal bir bileşikteki bağlarıkoparmak için gerekli olan 1sı olup, bu enerjinin neredeyse tamamı sentez reaksiyonugerçekleştiğinde geri alınabilmektedir[5]. 


\section{Bulgular}

Çok çeşitli termal depolama sistemleri vardır. Bu sistemler; termal depolama materyali ve depolama için kullanılan materyali şarj etme yöntemi ile ayırt edilebilirler. Bu sistemlerin diğer özellikleri arasında;ısısının depolanma süresi, depolanan ısı miktarı, ısı değiştiricilerin tasarımı ve ısı dağıtım sistemi sayılabilir. Termal enerji depolama sistemini tasarlayanların seçilen sistemin alan 1sıtma sisteminin maliyetini, güvenilirliğini ve performansını nasıl etkileyeceğini iyi analiz etmesi gerekmektedir. Temelde tasarlanan sistem güneş enerjisinin bir yoğunlaştırılmış güneş toplayıcisı tarafindan toplanıp isıtılan havanın bir fan, blower kullanmak suretiyle tamamen yalıtılmış depoya iletilmesi üzerine kuruludur.

\subsection{Güneş Kollektörü ve Alıcı}

Enerji Bakanlığınca hazırlanan, Türkiye Güneş Enerjisi Potansiyeli Atlasına (GEPA) göre, ülkemizde yıllık toplam güneşlenme süresi 2.741 saat (günlük ortalama 7,5 saat), yıllık toplam gelen güneş enerjisi $1.527 \mathrm{kWh} / \mathrm{m}^{2}$.yll (günlük ortalama $4,18 \mathrm{kWh} / \mathrm{m}^{2}$.gün) olduğu tespit edilmiştir[6].

Yoğunlaştırma oranlarına ve farklı çalışma sıcaklığı seviyelerine sahip birçok tipte toplayıcı mevcuttur. Doğrusal parabolik toplayıcılar, bileşik parabolik toplayıcılar, Fresnel lensleri ve solar çanak toplayıcılar en yaygın güneş yoğunlaştırıcı toplayıcılardır.

Güneş termal sistemleri genel olarak düşük, orta ve yüksek sıcaklık sistemler diye ayrılabilir. Güneş 1şığı konsantrasyonu olmadan çalışan düşük sıcaklıklı güneş enerjisi sistemleri düşük dönüşüm verimliliğine sahiptir ve ev içi uygulamalarda kullanılmaktadır. Güneş 1şı̆ğ konsantrasyonu gerektiren orta ve yüksek sıcaklık güneş enerjisi sistemleri, daha yüksek dönüşüm verimliliğine sahiptir ve çok çeşitli uygulamalarda kullanılabilirler [7].

Bu çalışmada tasarlanan sistem için iki tip güneş kollektörü düşünülebilir. Bunlar Şekil 1 ve 2 de gösterilen parabolik çanak kollektörler ve parabolik oluk kollektörlerdir. Her iki toplayıcıda güneş radyasyonunu yoğunlaştırarak daha yüksek 1s1 elde etmektedir. Yoğunlaştırma oranlarıfarklılık göstermektedir (Tablo 1).

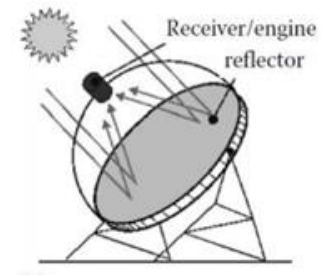

Şekil 1. Çanak Kollektör[8]

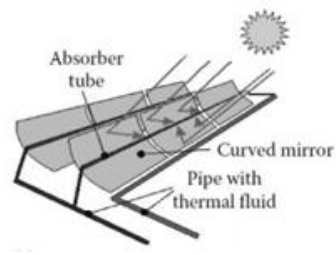

Şekil 2. Parabolik Oluk Kollektör[8] 
Tablo 1. Yoğunlaştırıcı özellikleri

\begin{tabular}{lll}
\hline Yoğunlaştırıcı Türü & Güneş radyasyon oranı & İşletme sıcaklığı aralığı $\left({ }^{\circ} \mathbf{C}\right)$ \\
\hline Çanak kollektör & $100-1000$ & $120-1500$ \\
Parabolik oluk kollektör & $15-45$ & $20-400$ \\
\hline
\end{tabular}

Toplayıcılarınetkin performansı için, güneşin açısal pozisyonunu takip etmesi ve onu izlemesi amacıyla doğrusal bir güneş izleyici(sun tracker) kullanılmaktadır. Toplayıcının isıl performansını artırmak için ise yüksek doğrulukta kontrol devresine sahip bir elektronik izleme sistemi kullanılmaktadır[9].

Yoğunlaştırıcılı toplayıcılarda üç tip kayıp meydana gelmektedir. Bunlar, optik kayıplar, emici borunun bulunduğu ortam sebebiyle oluşan ısıl kayıplar ve yoğunlaştıııcının geometrisinden kaynaklanan kayıplardır[8].

Tasarımda hangi yoğunlaştırııılı toplayıcı kullanılacağına karar vermek için, öncelikle ne kadar süreliğine bir termal enerji ihtiyacı var sorusuna cevap verilmelidir. Sonraki aşamalar, maliyetler, bölgesel ve yerel şartlar, güneşlenme süreleri göz önünde bulundurularak çanak tipi yoğunlaştırıcı veya oluk şeklindeki yoğunlaştırıcı kullanılmasına karar vermektir. Temelde daha önce de yapılan çalışmalarda ortaya konduğu gibi odak noktasına ve bu kısımdaki alıcıya önem verilmesi gerekir[7].

Alıcı tasarımları kendilerine özgü özellikler taşır. Örnek bir alıcı Şekil 3'de verilmiştir. Çanak tipi yoğunlaştırıcıda; odak noktasında yoğunlaştırıcıdan gelen 1şınları emecek şekilde, $10-20 \mathrm{~cm}$ dış ağız çapı olan ve orta kısmı ağzı daha geniş bir bardak şeklinde, üzerinde hava geçişine imkan veren 1-2 cm çapında delikli ve siyah renkli camdan, dişı çelikten, $25 \mathrm{~cm}$ uzunluğunda boru şeklinde izolasyonlu ve içerisinde kristal karbonize silikondan oluşan bir alıcı tasarlanabilir. $\mathrm{Bu}$ kısmın çıkışına spiral bakır borulu bir sistem konarak yaz aylarında bir Stirling buhar makinesiyle $\% 35^{\circ} \mathrm{e}$ varan verimde elektrik üretilebilir. Ya da TEG( termoelektrik jeneratör, Şekil 4) konularak veya daha yeni termoelektrik sistem konularak elektrik üretilebilir. Devamında izolasyonlu taşıyıcı boruyla sıcak havayı depoya iletecek bir fan ve ardından depo ünitesi gelmektedir.

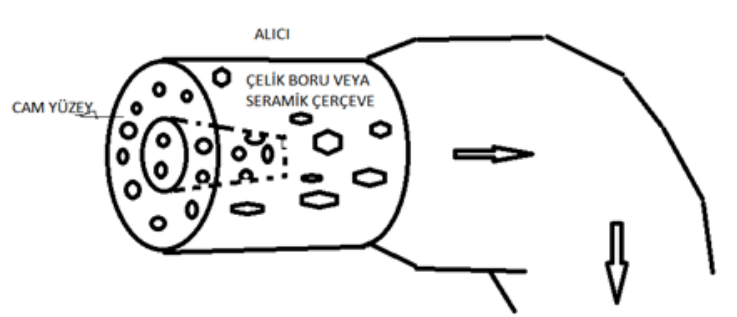

Şekil 3. Örnek bir alıc1

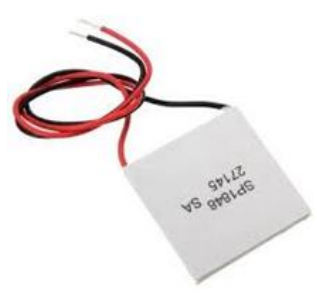

Şekil 4. Termoelektrik jeneratör 
Kollektörün verimini artırmak için pek çok çalışmada olduğu gibi bir solar izleyici kullanılabilir. $\mathrm{Bu}$ güneş 1şığı izleme sistemi için 1ş1k sensörlü bir DC-motor iki cds-photoresistör kullanılabileceği gibi piyasadaki herhangi bir ihtiyaca göre tek eksenli veya çok eksenli bir ta-kip sistemi kullanılabilir[9].

Oluk yoğunlaştırıcı kullanıldığı takdirde dikey olarak ve açılı bir şekilde 1sı ihtiyacının sonbahar ve kış aylarında daha fazla olması ve güneşin ülkemizde daha yatay konumda bulunduğu aylar dikkate alınarak açısı ayarlanabilir. Alıcı kısım içerisi ince bakır tel ya da alüminyum tel yumaklarıyla dolu bir çelik bir boru olabileceği gibi şayet elde edilebilirse renkli cam boru da olabilir. Alıcının içerisi yine kristal bir karbonize silikon veya bor (PCM) ile doldurulabilir.

Her iki tip yoğunlaştırıcı toplayıcının alıcısında dikkat edilmesi gereken; hava geçişini kolayca sağlayacak, verimi düşürecek toz ya da toza yakın materyallerden (silikon, bor) kaçınmaktır. Alıcıda kullanılan katı materyal yaklaşık 1-3 cm çapında olabilir. Bir diğer husus ise çanak tipi yoğunlaştırıcının daha verimli olduğunun unutulmamasıdır. Ayrıca yoğunlaştırıcıların tesis edildiği kısımlar güneşi en iyi alan kısımlar ve rüzgârı en az alan kısımlar olmalıdır. Rüzgârı tamamen kesmek amacıyla güneş ışınlarını engellemeyecek saydam bir materyalle kaplanabilir.

\subsection{Depolama Materyali}

Depolama materyali, kaynaklarda ısının tutulacağı ortam olarak geçmektedir. Temelde termal isı kapasitesi yüksek materyaller kullanılması(magnezyum tuğla, silikon ve bor gibi) tercih edilir. $\mathrm{Bu}$ maddeler bol bulunması, ucuz olması, 1sıl iletkenlik, 1sı karşısında genleşme katsayısının düşük olması gibi özellikler göz önünde tutularak seçilmelidir. Seçilen özellikler depo hacmi ile doğrudan bağlantılıdır. Başka katı maddeler(kaya, çakıl, doğal kauçuk vs.) veya sıvı maddelerde (sıvı tuz, su, yağ gibi) olabilir. Bu seçenekler ısıl depolamanın inşa edileceği yerin büyüklüğü, ya da istenen ısıl depolamanın büyüklüğü ile ilgilidir.

TED sistemleri için tipik parametreler; kapasite, güç, verimlilik, depolama süresi ve maliyet dahil olmak üzere aşağıdaki Tablo 2'de verilmiştir [2].

Tablo 2.TED sistemleri için tipik parametreler[2]

\begin{tabular}{cccccc}
\hline TED sistemi & Kapasite (kWh/t) & Güç (MW) & Verim (\%) & $\begin{array}{c}\text { Depolama } \\
\text { periyodu }\end{array}$ & $\begin{array}{c}\text { Maliyet } \\
(\boldsymbol{\epsilon} / \mathbf{k W h})\end{array}$ \\
\hline $10-50$ & $0,001-10$ & $50-90$ & günler/aylar & $0,1-10$ \\
& $50-150$ & $0,001-1$ & $75-90$ & saatler/aylar & $10-50$ \\
& $120-150$ & $0,01-1$ & $75-100$ & saatler/günler & $8-100$ \\
\hline
\end{tabular}

Aşağıdaki Tablo 3'te kum-kaya mineralleri, beton, ateş tuğlaları da dahil olmak üzere en yaygın kullanılan katı hal termal depolama malzemelerinin ana özelliklerini gösterilmektedir. Bu 
malzemeler $200{ }^{\circ} \mathrm{C}$ ile $1200{ }^{\circ} \mathrm{C}$ arasında çalışma sıcaklıklarına sahiptir ve mükemmel termal iletkenliğe sahiptir[2]. Şekil 5'de magnezyum ateş tuğlası 1sı depolama örneği tasarımı verilmektedir.

Tablo 3. Bazı termal depolama malzemelerinin temel özellikleri[2]

\begin{tabular}{ccccc}
\hline Depolama malzemesi & $\begin{array}{c}\text { Çalışma sıcaklığı } \\
\left({ }^{\circ} \mathbf{C}\right)\end{array}$ & $\begin{array}{c}\text { Yoğunluk } \\
\left(\mathbf{k g} / \mathbf{m}^{\mathbf{3}}\right)\end{array}$ & $\begin{array}{c}\text { Termal } \\
\text { Iletkenlik } \\
(\mathbf{W} /(\mathbf{m} . \mathbf{K}))\end{array}$ & $\begin{array}{c}\text { Özgül Sıcaklık } \\
\left(\mathbf{k J} /\left(\mathbf{k g} .{ }^{\circ} \mathbf{C}\right)\right)\end{array}$ \\
\hline Kum-kaya mineralleri & $200-300$ & 1700 & 1,0 & 1,30 \\
Betonarme & $200-400$ & 2200 & 1,5 & 0,85 \\
Dökme demir & $200-400$ & 7200 & 37,0 & 0,56 \\
NaCl & $200-500$ & 2160 & 7,0 & 0,85 \\
Dökme Çelik & $200-700$ & 7800 & 40,0 & 0,60 \\
Silika ateş tuğlası & $200-700$ & 1820 & 1,5 & 1,00 \\
Magnesia ateş tuğlası & $200-1200$ & 3000 & 5 & 1,15 \\
\hline
\end{tabular}

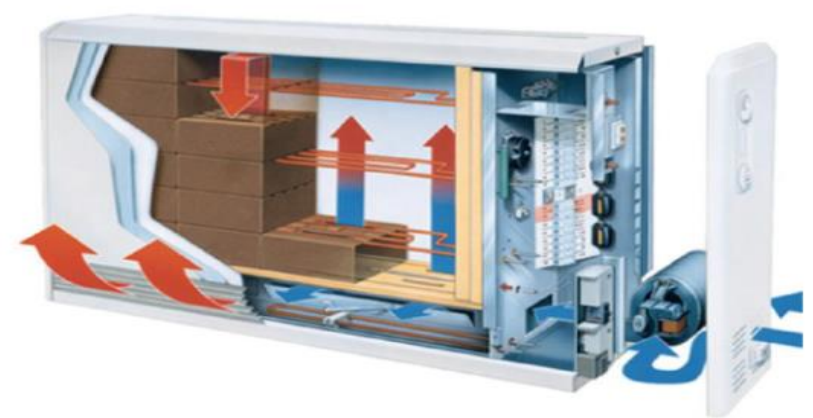

Şekil 5. Magnezyum ateş tuğla 1sı depolama ünitesi örneği

\section{Termal Depolama İçin Kullanılacak Malzemelerin Özellikleri}

Termal depolama sisteminin boyutu Isıtma gerektiren uygulama (1S1 yükü); 1sı kaynağı, BTU çıkış kapasitesi ve yanma süresi; depolama malzemesinin ısıl kapasitesi;depolama süresi;tahmin edilen bekleme 1sı kaybı gibi faktörlere bağlıdır.Sistem verimliliğini en üst düzeye çıkarmak için termal depolama sisteminin optimum boyutlandırılması önemlidir. Ek bir 1sıtma kaynağ olmadan, olması gerekenden daha küçük bir boyutlandırma yapılan termal depolama sistemleri, 1sıttma taleplerini karşılamak için yetersiz olacaktır.

Araştırmalarda depo için çok fazla seçenek mevcut değildir. Sıcak su için klasik depolar piyasada mevcuttur. Bu çalışma için tasarımda kullanılacak deponun en önemli ayrıntısı dizaynı olacaktır. Galvanizli çelik malzeme veya yerin durumuna göre izolasyonlu tuğladan örülmüş ve ayrıca izole edilmiş depolar kullanılabilir. Akışkan olarak hava ise kullanılacaktır. Sistemin tamamen kapalı devirde çalışması halinde karbondioksit de kullanılabilir. Depo çalışma mantı̆̆ı; yerin ve şartların durumuna göre ayarlanabilir. Literatürde üstten sıcak havanın girişi ile ve aşağıya doğru hareket 
etmesi sırasında sıcaklığın üstte kalmasını sağlayan bir sistemin daha verimli olduğuanlaşılmıştır[1]. Depo üstte kullanım için bir kapakla ısı geçişi kontrolü sağlanan, hem hava hem de sıvı kullanımına uygun eşanjör odası bulunacaktır. Bu kısım aynı zamanda depolama malzemesinin doldurulup boşaltılması için kapak vazifesini görecektir. Kollektördenblower (hava körügü) vasıtasıyla gelen sıcak hava, deponun alt kısmından üste, kapak altı seviyesinden dirsekli çelik boruyla içeri girecek, deponun alt kısmındaki kontrollü kapaktan ısıyı bırakarak çıkacaktır. Deponun diş kısmı ise, deponun koyulduğu yere göre izolasyon malzemesi seçilerek izolasyonu yapılmalıdır.Şekil 6'da örnek bir depo modeli gösterilmektedir.

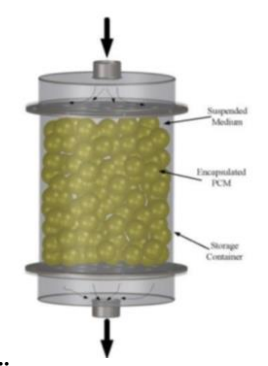

Şekil 6. Örnek bir depo modeli

\section{Termal Enerji Depolama Sistemi Tasarımı}

Çalışmanın bu kısmında çeşitli kabuller ve literatürde yer alan veriler kullanılarak bir termal enerji depolama tasarımı ve maliyet analizi yapılacaktır.

Kış aylarında standart bir evindoğalgaz tüketimi bulunduğu bölgenin iklim koşullarına, evin büyüklüğüne, yalıtımına vb. koşullara bağlı olarak değişmekle birlikte literatürde aylık ortalama $300 \mathrm{~m}^{3}$ civarında olduğu anlaşılmaktadır[10].

$1 \mathrm{~m}^{3}$ doğalgaz $=10,64 \mathrm{kWh}=9146 \mathrm{kcal}=38,3 \mathrm{MJ}$ 'dür[12,13].

Buna göre standart bir evin aylık enerji ihtiyacı 3192 kWh'lik bir enerjiye karşılık gelmektedir.

Buda günlük olarak;

$3192 \mathrm{kWh} / 30$ gün $=106,4 \mathrm{kWh} /$ gün enerji ihtiyacı demektir.

1 aylık bir termal enerji depolaması düşünüldüğ̈̈ varsayıldı̆̆ında;

Verim \% 75( \% 70' in üzeri, $\left.450^{\circ} \mathrm{C}\right)[13,14]$ olarak kabul edilirse,

3192kWh/0.75 = 4256kWh/ay bir enerji ihtiyacı anlamına gelmektedir.

Bu da 4256kWh= $15318 \mathrm{MJ}$ 'e eşit olacaktır. 
$\mathrm{Bu}$ durumda standart bir ev için $4256 \mathrm{kWh} / 30$ gün $=141,87 \mathrm{kWh} /$ gün termal enerjiyeihtiyac1 olacaktır.

\subsection{Termal Enerji Depolama Sistemi Tasarımında Kullanılacak Kabuller}

$\mathrm{Bu}$ çalışma kapsamında tasarımı yapılacak termal enerji depolama sisteminde kullanılacak kabuller aşağıda sıralanmıştır.

- 150-300 cm çapında (2,54 m²-7.06 m²alanlı) çanak toplayıcı (krom saç üzerine ayna), 1001000 yoğunlaştırma oranı, $120^{\circ} \mathrm{C}-1500{ }^{\circ} \mathrm{C}$ çalışma sicaklığı aralığı[15],

- $25 \mathrm{~cm}$ çapında alıcı (çelik boru,kristalize siliconkarbid, delikli cam)

- Tek eksenli güneş takip cihazı (solar tracker),

- Blower (debisi yaklaşık 0,147 m³/s ve elektrik tüketimi $0.15 \mathrm{kWh}$ ),

- Çelik depo $2 \mathrm{~mm}$ et kalınlığında $3 \mathrm{~m}^{3}$ hacimli Silindirik veya dikdörtgen tank,

- Magnezyum depolama ortamı ( tuğla veya 2-5 cm çapında çakı1 formunda)

- Alıcıdan depoya kadar iletim ve depo giriş çıkışları için çelik boru (15 cm çapında,2 mm kalınlığında, $5 \mathrm{~m}$ boyunda),

- İzolasyon malzemesi( taş yünü veya eşdeğeri),

- Isı değiştirici (eşanjör),

- Çelik boru $15 \mathrm{~cm}$ çapında $1 \mathrm{~mm}$ et kalınlığında(depo üst kısmına yerleşecek),

- Elektrik, Elektronik aksam(zamanlayıcı vb.),

- Günlük ortalama elektriksel enerji 4,18 kWh/m².gün[6],

- Günlük ortalama termal enerji $400 * 150 \mathrm{Watt} / \mathrm{m}^{2} .{ }^{\circ} \mathrm{C}[16]$,

- $\Delta \mathrm{T}=400,800,1200{ }^{\circ} \mathrm{C}\left(120-1500{ }^{\circ} \mathrm{C}\right)$,

- Sistem ömrü 20-30 y1l,

- Toplam sistem verimi \% 90,

- Bekleme 1sı kayıpları (yüzeye ve izolasyona bağlı) olarak \% 10 dan daha az olacağı kabul edilmiştir.

\subsection{Termal Enerji Depolama Sistemi Tasarımı Maliyet Analizi}

Aşağıda Tablo 4'te termal enerji depolama sistemi tasarımında kullanılacak malzemelerin birim maliyetleri verilmiştir.Tablo 5'te ise TED tasarımında kullanılacak depo malzemesi ve enerji 
depolama malzemelerinin maliyetleri ve Tablo 4'de yer alan malzemelerle birlikte tüm TED sistemi tasarımının toplam maliyetleri verilmiştir.

Tablo 4. Termal Enerji Depolama sistemi tasarımında kullanılacak malzemelerin birim maliyetleri

\begin{tabular}{lc}
\hline Malzeme & Maliyet $\mathbf{( \$ )}$ \\
\hline Güneş Takip Cihazı & $105,00 \$$ \\
Çanak & $434,00 \$$ \\
Fan & $60,00 \$$ \\
Taşıyıcı Boru & $39,00 \$$ \\
İzolasyon Malzemesi & $46,00 \$$ \\
Isı Eşanjörü & $26,00 \$$ \\
Diğer Giderler & $86,00 \$$ \\
\hline Toplam & $\mathbf{7 9 6 , 0 0 \$}$ \\
\hline
\end{tabular}

Tablo 5. Termal Enerji Depolama sistemi depo, depolama malzemesi ve toplam maliyetler

\begin{tabular}{cccc}
\hline Depo Malzemesi & Depolama Malzemesi & Maliyet $\mathbf{\$}$ ) & $\begin{array}{c}\text { TED Malzeme } \\
\text { maliyetleri* ile birlikte } \\
\text { toplam maliyet(\$) }\end{array}$ \\
\hline \multirow{2}{*}{ Çelik } & Tuğla & $2358 \$$ & $3157 \$$ \\
& Çakıl & $911 \$$ & $1710 \$$ \\
Beton & Tuğla & $1985 \$$ & $2784 \$$ \\
& Çakıl & $393 \$$ & $1193 \$$ \\
\hline
\end{tabular}

TED sistemlerinin kullanılmasıyla ülke genelinde fosil yakıtlardan sağlanacak \%10‘luk tasarruf ile emisyonlarda beklenen azalma yilda en az 5,6 milyon ton $\mathrm{CO}_{2}, 18900$ ton $\mathrm{SO}_{2}$ ve 21600 ton $\mathrm{NO}_{\mathrm{x}}$ olacağı tahmin edilmektedir[17].

\section{Sonuç}

Teknolojinin gelişmesi ile birlikte hayatımıza sürekli yenilikler gelmektedir. Ülkelerde gelişmişlik düzeyi arttıkça buna paralel olarak enerji tüketiminde de hızlı bir artış gözlemlenmektedir. İnsanoğlunun çağa ayak uydurabilmek, zamanı iyi kullanabilmek ve daha konforlu yaşamak adına sürekli enerjiden yararlanması gerekiyor. Birçok ülkede olduğu gibi Türkiye'de de enerji yaygın olarak fosil yakıtlardan elde edilmekte ve tükettiğimiz enerjinin büyük çoğunluğu ithal edilmektedir. Fosil yakıtların çevreye olan olumsuz etkileri, yakın gelecekte tükenebilecek olması ve enerjinin ithal edilmesiçevresel sorunlara ve enerji güvenilirliği kaygılarına da neden olmaktadır.

Kentleşmenin ve endüstriyel gelişimin kaçınılmaz sonucu gibi görünen sera gazları etkisini artan bir şekilde hissetmeye başladığımız günümüzde konu ile ilgili akademik ve ticari kurumlar 
alternatif enerji kaynakları üzerindeki Araştırma-Geliştirme (Ar-Ge) çalışmalarına önem vermeye başlamıştır. 1970 petrol krizi sonrası başlatılan çalışmalar, çevresel boyutlarında devreye girmesi ile ivme kazanmıştır. $\mathrm{Bu}$ çalışmalar içinde, mevcut yenilenebilir enerji kaynaklarını değerlendirmeye yönelik olarak, termal enerji depolama (TED) yoluyla enerjinin kullanılması yöntemleri önemli bir yer tutmaktadır. Dünyada geniş bir şekilde kullanılan bu sistemler ülkemizde henüz yaygın bir kullanıma sahip değildir. Kısa süre içerisinde yapılan çalışmalar sonucu,TED teknolojilerinin çevre ile dost ve ekonomik olduğunu gösteren uygulamalar hızla artmıştır.Bu çalışma kapsamında TED sisteminin enerji temin etmedeki öneminden ve ayrıca bir ailenin oturacağı standart bir ev için bir termal enerji depolama sisteminin tasarımının ortalama maliyeti analiz edilmiştir.

\section{Referanslar}

[1] Sarbu I, Sebarchievici C. Solar Heating and Cooling Systems: Fundamentals, Experiments and Applications. Academic Press, 2016.

[2] Sarbu I, Sebarchievici C. A Comprehensive Review of Thermal Energy Storage. Sustainability 2018; 10: 2-32.

[3] Thermal energy storage: Technology brief. /publications/2013/Jan/Thermal-energystorage, /publications/2013/Jan/Thermal-energy-storage (18 Ekim 2019).

[4] Thermal_storage, http://www.cchrc.org/sites/default/files/docs/thermal_storage.pdf (accessed 11 November 2019).

[5] Esgel

H. KordiyeritEsaslıSeramikMalzemedenYapılmışTermalEnerjiDepolamaSistemininAnalizi. Thesis, EnerjiEnstitüsü, https://polen.itu.edu.tr/handle/11527/12852 (2014, 11Ekim2019).

[6] T.C. EnerjiveTabiiKaynaklarBakanlığı - Güneş. enerji.gov.tr, http://www.enerji.gov.tr/trTR/Sayfalar/Gunes (8 Ekim 2019).

[7] Pavlovic S, Bellos E, Stefanovic V, et al. Design, simulation and optimization of a solar dish collector with spiral-coil thermal absorber. Thermsci 2016; 20: 1387-1397.

[8] Concentrating solar thermal power plants - PDF, https://docplayer.net/55192891Concentrating-solar-thermal-power-plants.html (11 Ekim2019).

[9] Ahmed MA. Construction and Operation of Solar Energy Dish for Water Heating. BSJ 2017; 14: 797-800.

[10] Tolgahan Y. Kombi Hesaplamaları, http://www.tolgahan.net/?p=283 (13 Ekim 2019). 
[11] Doğalgazmetreküpfiyatıkaç lira? Gazelektrik, https://gazelektrik.com/s-s-s/dogalgazmetrekup-fiyati (11 Ekim 2019).

[12] Unit Converter, https://convertlive.com/ (10Ekim 2019).

[13] Optical Design of a Solar Dish Concentrator Based on Triangular Membrane Facets, https://www.hindawi.com/journals/ijp/2012/391921/ (13 Ekim 2019).

[14] Mehla A, Kumar P, Bhool R, et al. Regeneration of Soild Desiccant by Solar Parabolic Dish Collector in India: An Experimental Analysis. 3: 723-734.

[15] Alva G, Lin Y, Fang G. An overview of thermal energy storage systems. Energy 2018; 144: 341-378.

[16] Eswaramoorthy M, Shanmugam S. The Thermal Performance of a Low Cost Solar Parabolic Dish Collector for Process Heat. Energy Sources, Part A: Recovery, Utilization, and Environmental Effects 2012; 34: 1731-1736.

[17] Yilmaz MÖ. YeraltıTermalEnerjiDepolamadaKullanılanFarklıDolguMaddelerininTermalÖzelliklerinin Araştırılması. 78. 